\title{
Por que é a Europa uma região pacífica? Um novo quadro de análise
}

Why is Europe a peaceful region?

Par quoi l'Europe est une région pacifique? Un nouveau cadre d'analyse

\section{Rodrigo Tavares}

\section{OpenEdition}

\section{Journals}

Edição electrónica

URL: http://journals.openedition.org/rccs/1021

DOI: $10.4000 /$ rccs. 1021

ISSN: $2182-7435$

\section{Editora}

Centro de Estudos Sociais da Universidade de Coimbra

Edição impressa

Data de publição: 1 Junho 2005

Paginação: 97-112

ISSN: 0254-1106

\section{Refêrencia eletrónica}

Rodrigo Tavares, «Por que é a Europa uma região pacífica? Um novo quadro de análise », Revista Crítica de Ciências Sociais [Online], 71 | 2005, colocado online no dia 01 outubro 2012, criado a 20 abril 2019. URL : http://journals.openedition.org/rccs/1021 ; DOI : 10.4000/rccs.1021 


\section{Por que é a Europa uma região pacífica? Um novo quadro de análise}

Apesar de o processo de pacificação da Europa ter tido início nos anos 50, foi a queda do Muro de Berlim, em 1989, que originou um crescimento exponencial de publicações vocacionadas para a descrição e explicação deste fenómeno. Após o entusiasmo teórico inicial, o actual decréscimo dos produtos da investigação é inversamente proporcional ao crescimento de laços de integração na União Europeia. Este artigo defende que as velhas ferramentas epistemológicas de compreensão da pacificação da Europa se tornaram obsoletas por estarem enraizadas num contexto regional ultrapassado. De forma a ultrapassar esta limitação, apresenta-se um novo quadro de interpretação baseado na ideia de Paz Regional e Aglomerados de Segurança (PRAS). A PRAS Europeia é abordada numa perspectiva histórica e abrangente.

\section{Introdução}

Desde a emergência da "ideia de Europa" com o Império Romano, a história da Europa tem sido, uma história de guerra entre micro- e macro-entidades políticas em luta pelo poder, pelo domínio e pela influência.

Das setenta e cinco guerras inter-estatais levadas a cabo entre 1815 e 1993, trinta e uma envolveram um ou mais estados europeus de um dos lados. Dos 31 milhões de baixas em todas as guerras inter-estatais neste período, 25 milhões registaram-se em trinta e uma guerras entre estados europeus (Gleditsch, 1995).

Apesar deste passado desolador, a Europa viveu, ainda assim, períodos pacíficos no passado. A Escandinávia, por exemplo, manteve-se à margem de práticas violentas durante longos períodos. A Islândia está em paz desde 1262, a Noruega entre 1371-1612 e entre 1814-1940 e a Suécia,

\footnotetext{
${ }^{1}$ Este artigo foi elaborado no âmbito do meu Doutoramento, financiado pela Fundação para a Ciência e Tecnologia. Agradeço a Bev Crawford, Stefano Guzzini, Oliver Richmond, Jerry Sanders e Fred Söderbaum pelos seus comentários. O artigo foi apresentado na Conferência do Consórcio Europeu para a Investigação Política/Grupo de Relações Internacionais que teve lugar na Haia em Setembro de 2004.
} 
ininterruptamente, desde 1721 (Kacowicz, 1998:14). A ordem criada com o Concerto Europeu (1815) consolidou, deliberadamente, um acordo que estabilizaria a Europa até 1848. Após a Guerra da Crimeia e as guerras de unificação nacional da Itália e Alemanha, emergiu uma nova ordem pacífica Europeia que duraria até à eclosão da Primeira Guerra Mundial. No entanto, estas experiências pacíficas na história europeia não são de forma alguma o padrão mais comum, como é comprovado pelas duas Guerras Mundiais na primeira metade do século XX.

Apesar destes antecedentes, ou talvez por causa deles, a arquitectura de segurança da Europa, no pós-II Guerra Mundial, foi transformada de forma tão drástica que resultou na exclusão da violência inter-estatal como uma estratégia aceitável para resolver litígios. É hoje claramente reconhecido que a União Europeia é o exemplo mais destacado dos efeitos positivos da regionalização na construção da paz (peace-building)2.

Os acontecimentos decisivos que tiveram lugar na Europa no final dos anos 80 provocaram a disseminação de publicações que ora exploravam os cenários de futuro para a Europa (Hettne, 1988; Buzan et al., 1990), ora pretendiam descrever e explicar o processo de pacificação da Europa Ocidental após a Segunda Guerra Mundial. Essas publicações foram marcadas por três características fundamentais. Em primeiro lugar, apesar de oferecerem uma explicação consistente para o triunfo da paz após a Segunda Guerra Mundial, a sua descrição e fundamentação da manutenção e desenvolvimento desta paz é muito mais frágil. Manter-se-ão os instrumentos que configuraram a paz nos anos 50 adequados ao contexto actual? Em segundo lugar, sobressai nestas publicações mais recentes uma polarização epistemológica entre perspectivas realistas e liberais. As primeiras centravam-se na distribuição bipolar do poder, no imperativo da igualdade militar entre a União Soviética e os Estados Unidos, no impacto de uma "ameaça externa" como impulso para a cooperação e na dissuasão nuclear (Mearsheimer, 1990; Gaddis, 1987; Waltz, 1993). As segundas tinham como prioridade a institucionalização dos processos de tomada de decisão, a intensificação da interdependência económica e a democratização (van Evera, 1990/91; Maoz e Russett, 1992). Em terceiro lugar, estas publicações privilegiam os níveis de análise nacional (no caso do liberalismo) ou global (no caso do realismo) em detrimento do nível regional como quadro apropriado de explicação. Nas palavras de Mearsheimer "a chave para a guerra e para

\footnotetext{
2 "Peace-building" ou a construção da paz é tido aqui como um conceito abrangente que inclui prevenção de conflitos, gestão de conflitos, resolução de conflitos e reconstrução e reconciliação pós-bélica.
} 
a paz [na Europa] encontra-se mais na estrutura do sistema internacional do que na natureza dos Estados individuais" (1990: 12. sublinhado meu). Se era suposto o nível global constituir uma sólida base de explicação, por que razão não se transformou a Europa, tal como previsto por Mearsheimer (1990), num complexo regional dilacerado por nacionalismos, conflitos étnicos e instabilidade, com o final da Guerra Fria? O nível nacional também não se oferece como quadro geral de compreensão da paz na Europa. Serão as democracias em Espanha, em França e no Reino Unido um modelo a seguir, na forma como lidam com a agitação interna pela distribuição do poder?

Este artigo assume uma posição diferente. Em primeiro lugar, ao contrário da maior parte da literatura, analisarei o modelo de paz europeu num plano regional. Em segundo lugar, lerei a construção da paz na Europa numa perspectiva histórica. Apesar de não concordar com o determinismo histórico, entendo que a História nos guia numa direcção determinada. Em terceiro lugar, a perspectiva aqui apresentada pretende avaliar as mudanças ocorridas no processo. A construção da Europa contemporânea é um fenómeno complexo e heterogéneo que não pode ser integralmente compreendido através de abordagens herméticas, unidimensionais ou estáticas. Por último, pretendo estudar esta construção de forma sistémica. Somente uma perspectiva holística pode dar conta dos elementos de ligação num processo complexo que está a ser construído por várias forças sobrepostas.

Este artigo está dividido em duas partes. Na primeira, apresentarei um novo quadro de análise para compreender a relação entre regionalização e paz. Este novo enquadramento é construído sobre o conceito de "Paz Regional e Aglomerados de Segurança" (PRAS). Na segunda parte, aplicarei sucintamente este quadro de análise à Europa, analisando os instrumentos e os actores da paz e o padrão de conflito que define os diferentes tipos de PRAS. Sustentarei que a Europa é actualmente uma comunidade de segurança PRAS, embora aspire, ao nível das elites, a tornar-se numa entidade política regional institucionalizada.

\section{Uma nova abordagem: a regionalização da paz}

Ao contrário da grande maioria das teorias e abordagens sobre a paz regional (Deutsch et al., 1957; Singer e Wildavsky, 1993; Lake e Morgan, 1997; Kacowicz, 1998), o modelo aqui apresentado pretende explicar a relação entre regionalismo e paz com base na sua natureza abrangente e multidisciplinar. Defendemos que é necessário identificar e reunir algumas variáveis para compreender o fenómeno da paz e segurança regionais. Propomos, 
neste artigo, que a constituição genética da Paz Regional e dos Agrupamentos de Segurança (PRAS) é composta por oito variáveis (nominais e ordinais):

- Nível de integração regional (baixo, médio, médio/alto e alto);

- Distribuição do poder entre as principais unidades numa região (uni-hegemónica, multi-hegemónica, desequilibrada mas não hegemónica, igualitária);

- Factores que levam ao conflito (território, criação do Estado ou de autonomia, comércio/recursos, protecção de nacionais no estrangeiro, disputas étnicas/religiosas, apoio a aliados, libertação ideológica, composição do governo, manutenção da integridade do Estado/ Império, aplicação dos conteúdos de um tratado, manutenção da dominação regional, proliferação de armas de destruição em massa, terrorismo);

- Potenciais agentes de paz (ex.: Estado, organização regional, sociedade civil regional, agentes económicos regionais);

- Instrumentos de paz (ex.: equilíbrio regional de poder, hegemonia regional, dissuasão nuclear, zonas preferenciais de comércio, identidade regional, integração regional, micro-regionalização);

- Padrão de conflito regional (propensão para a violência, ausência de violência, comunidade de segurança pluralista, propensão para a paz positiva);

- Influência do nível global (materializada nas Nações Unidas, na interferência das grandes potências e nas diferentes intensidades de efeitos da globalização);

- Natureza do sistema político dos membros (segundo uma escala democrático - não democrático).

Ao utilizar um modelo estruturado em oito variáveis para compreender a paz e a segurança regionais, não pretendemos sugerir que o valor das variáveis muda linear e deterministicamente segundo regras de causalidade. O modelo pretende principalmente analisar a fronteira entre, por um lado, o genoma específico de cada região e, por outro lado, as variáveis que tendem a alterar-se de forma similar independentemente da região à qual se referem. Nenhuma PRAS é idêntica a outra quanto ao nível de variação dos componentes que a definem. No entanto, apesar do dinamismo e da especificidade inerentes às PRAS, quatro grandes tipos de descritores podem ser estudados em Relações Internacionais: "complexo regional", "sociedade regional", "comunidade regional" e "entidade política regional institucio- 
nalizada". Ao conjugar as oito variáveis em simultâneo, os aglomerados regionais podem ser descritos da seguinte forma:

- Complexos regionais. Caracterizam-se por baixos níveis de integração regional, afectados por conflitos inter- e intra-estatais (e eventualmente pelo colapso do sistema). Correspondem a regiões onde o principal actor internacional - o Estado - luta por segurança, sobrevivência e poder. A paz é vista como a ausência de guerra e os instrumentos utilizados para a atingir são eficazes quanto à capacidade de dissuasão mas insuficientes para a obtenção de mais equidade, bem-estar e desenvolvimento. O papel de outros agentes para além do Estado é normalmente menosprezado. Os Estados podem não ser governados por instituições plurais e democráticas. A actual situação no Sul da Ásia, devastado por divisões étnicas e políticas internas no Sri Lanka, Nepal, Paquistão e Índia, e pelo antigo conflito inter-estatal entre a Índia e o Paquistão, é disso uma expressão relevante.

- Sociedades regionais. O crescimento das interacções e ligações evidencia-se no estabelecimento de laços formais (organizações regionais) e informais (partilha de regras e valores comuns) entre actores estatais, da sociedade civil e do mercado. A possibilidade de atingir uma paz positiva não é ainda a principal preocupação destes actores, mas a existência da região revela-se mais através de práticas de amizade do que de inimizade. Actualmente, diversas regiões no mundo encontram-se neste nível, como são os casos do Sudoeste Asiático e da América do Sul. - Comunidades regionais. Neste nível, a existência de uma zona de paz é reconhecida e a paz negativa inter-estatal é dada como adquirida. As regiões ganham um estatuto internacional e por isso começam a desempenhar o papel de doadores (ajuda externa), facilitadores da paz ou a comprometerem-se com iniciativas de manutenção da paz. Os Estados membros da região são democracias pluralistas e estão envolvidos em formas de integração regional de alto nível. A União Europeia é, até agora, o único caso manifesto deste patamar.

- Entidades políticas regionais institucionalizadas. A soberania tradicional é abandonada e novos mecanismos supranacionais de elaboração de políticas (policy making) englobam, não apenas, os anteriores Estados independentes, mas também as comunidades locais, as micro-regiões e, eventualmente, as organizações da sociedade civil. Os grupos étnicos e políticos que mantinham relações hostis com o poder central, ao nível do Estado, terão novos meios para discutir e materializar as suas exigências. 
FIGURA 1 - A constituição de um Aglomerado de Paz e Segurança Regional

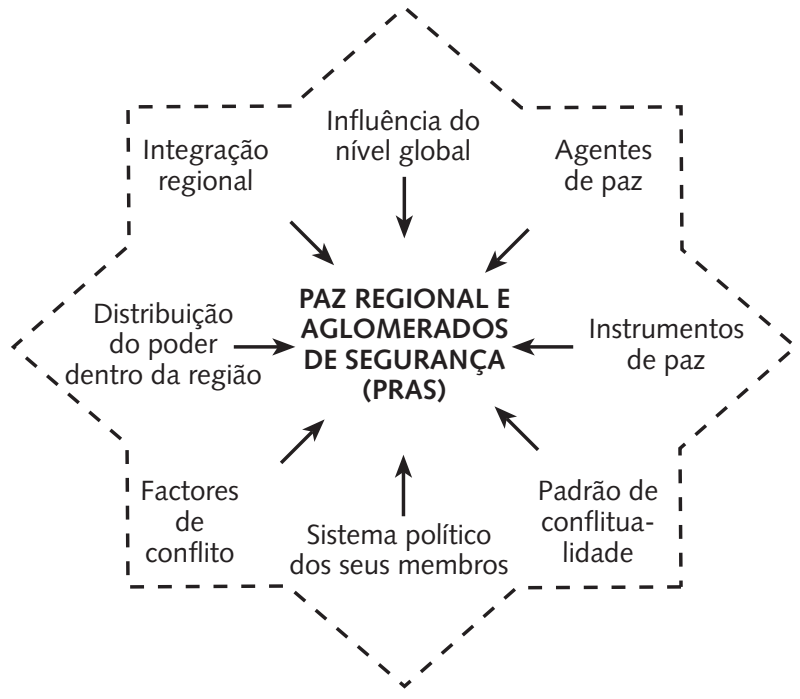

Os PRAS não são estruturas estáticas nem permanentes das relações internacionais. A sua existência requer apenas a fixação e a criação de relações de interdependência entre agentes locais. Para que os PRAS mudem, são necessárias alterações significativas nos seus elementos constitutivos. Neste artigo, definimos um Complexo de Paz e Segurança Regional (CPSR) como um conjunto de unidades inter-relacionadas fixadas num território que partilham o mesmo ambiente de segurança regional.

Defendemos que a criação e manutenção de aglomerados regionais não depende da decisão dos agentes nacionais e regionais de criarem "zonas de paz e segurança”. Na nossa perspectiva, os aglomerados regionais de paz e segurança surgem espontaneamente como um facto observável nas relações internacionais com a fixação das comunidades e, principalmente, com a formação do Estado moderno.

Tal como sublinhou Mouritzen (1995), o sistema internacional foi, durante um largo período de tempo, marcado por tribos bárbaras que se movimentavam em longas distâncias. E com a instabilidade geográfica e a mobilidade dos principais actores, nenhum ambiente regional estável alguma vez emergiu. Defendemos que todas as construções regionais, independentemente da sua orientação política, âmbito, duração, área de intervenção (focal area), nível de coesão e mandato, são, na realidade, PRAS. A fixação e regionalização dos agentes e práticas locais contêm inevitavelmente um elemento de segurança que nem sempre é evidente. 


\section{Europa: a construção de uma região pacífica}

De acordo com o quadro de análise atrás enunciado, a Europa evoluiu de um complexo regional a comunidade regional, num processo que foi sustentado pela institucionalização trazida pela União Europeia. A transição entre diferentes PRAS não decorreu, porém, de um objectivo racional ou de uma escolha unívoca de todos os actores verticais envolvidos no processo. Em vez disso, o progresso entre os diferentes PRAS evidenciou muitos recuos e decisões precipitadas. Quando, por exemplo, a Europa era um complexo regional, alguns acontecimentos, como a assinatura dos Tratados de Vestefália (1648), reflectiram um nível de entendimento entre as partes envolvidas que poderiam levar-nos a qualificar a região como uma sociedade regional. Por outro lado, a "Crise da Cadeira Vazia", de 1965, provocada pela ausência dos representantes Franceses do Conselho de Ministros e do Comité de Representantes Permanentes na época de De Gaulle, ou ainda a rejeição do TUE (Tratado da União Europeia ou Tratado de Maastricht) pelos Dinamarqueses, no referendo de 1992, são casos flagrantes de que a UE não foi estabelecida como sociedade regional nos anos 60 nem como comunidade regional nos anos 90, ao contrário do que poderíamos esperar do ponto de vista teórico. Embora o esquema aqui apresentado implique alguma progressão, não é sugerida uma linearidade estável nem a ideia de evolução.

\section{Europa: complexo regional}

Os contornos de um complexo regional europeu tornaram-se visíveis com a formação do sistema de Estados europeu (Buzan et al., 1990). Historicamente, os Tratados de Vestefália (1648), Utreque (1713) e Rastatt (1714) criaram um sistema baseado na soberania nacional, no não-reconhecimento de uma autoridade superior, na demarcação das fronteiras nacionais e, principalmente, no postulado de não-ingerência nos assuntos internos dos Estados. No complexo regional europeu, as relações internacionais eram dominadas pelo interesse nacional dos Estados independentes e os contactos entre estes eram mais propensos à violência do que para à cooperação pacífica. Este princípio, segundo o qual uma ordem moral de fundamento teológico foi preterida em nome do interesse nacional, foi introduzido na Europa pela persistente tentativa do Cardeal Richelieu de contrariar o Império dos Habsburgos, em benefício da França.

De acordo com o quadro de análise proposto neste artigo, no que diz respeito à acção ("agency”), um complexo regional é dominado pelo Estado enquanto actor central na gestão regional dos conflitos e na construção da paz. Esta centralidade hegemónica do Estado nas relações sociais globais 
impede outros actores, como a sociedade civil e os agentes económicos privados, de levar a cabo actividades complementares. Neste contexto, os instrumentos usados para atingir a paz são insuficientes na sua capacidade de construir uma paz positiva. Quais são estes potenciais instrumentos? O primeiro, a guerra, é usado repetidamente como um meio racional para estabelecer a ordem e a estabilidade internacionais. Além da guerra, também o equilíbrio de poderes e os acordos militares colectivos servem como potenciais instrumentos de paz.

Neste nível, as relações sociais de tipo regional foram, fundamentalmente, conduzidas por práticas de hostilidade, sendo as possibilidades de paz positiva limitadas pelo primado da segurança, do interesse nacional e da busca do poder. A guerra era vista como um instrumento nacional para conseguir a paz e a paz era vista de forma negativa como a ausência de violência. Num complexo regional, as iniciativas regionais para promoção o bem-estar e desenvolvimento regionais (paz positiva) são raras ou não existem.

Apesar de alguns destes instrumentos terem sido por vezes capazes de dissuadir os Estados do uso da violência, um olhar sobre o passado violento da Europa mostrará que a taxa de sucesso era, em geral, baixa.

\section{Europa: sociedade regional}

Uma sociedade regional PRAS implica que os actores envolvidos numa região alcançam um entendimento mais consistente dos valores e regras que permitem ultrapassar as principais divergências. Este processo, numa sociedade regional, pode ser feito através de instrumentos de paz informais e/ou formais.

A Europa oferece muitos exemplos de instrumentos de paz informais, através de ensaios de procedimentos e valores para a gestão da violência, valores comuns e confiança nas normas comuns. A Paz de Vestefália constitui uma ilustração disto mesmo. Holsti interpretou-a como um acontecimento especialmente importante "na afirmação da ideia de solidariedade e na enfatização da interdependência da Europa. Esta é a ideia de uma sociedade de Estados; um tipo de corpo político com características comunitárias, incluindo as obrigações recíprocas baseadas na igualdade” (1991:39). A par disto vem a ideia de uma "solidariedade de facto", como o primeiro marco no caminho para a paz na Europa, tal como exprimiu Robert Schuman na Declaração de 1950. Em 1975, a Conferência para a Segurança e Cooperação na Europa, celebrada em Helsínquia, também incorporou o espírito de tolerância entre os Estados Europeus. Dado o turbulento ambiente internacional da Guerra-Fria, o compromisso dos Estados participantes "para 
com a paz, segurança e justiça e a continuação do desenvolvimento de relações amigáveis e de cooperação" (Acta Final, 1975) foi, apesar da óbvia aparência retórica, um significativo passo em frente.

A grande diversidade de visões da segurança e os interesses nacionais em conflito reforçaram-se mutuamente neste nível e evoluíram de forma complementar e mútua mais do que numa direcção competitiva e divergente. Isto pode levar a uma institucionalização das estruturas cognitivas e a um aprofundamento gradual da confiança e receptividade mútuas. Para além dos passos informais em direcção à paz, os instrumentos formais, nomeadamente organizações e instituições sociais, desempenham um papel crucial neste processo, levando a uma maior construção comunitária e regional. A grande diferença entre um complexo regional e uma sociedade regional não é o abandono dos interesses nacionais em nome da confiança e valores comuns. A moralidade não substitui a política de poder ("power politics"). A diferença fundamental é que, pela primeira vez, os interesses nacionais dos Estados independentes são alcançados através da cooperação e da integração e não através do proteccionismo, da auto-suficiência ou da guerra. A segunda grande diferença é que, numa sociedade regional, não existem acordos de segurança cujo objectivo seja confrontar ou materializar uma oposição entre diferentes Estados na mesma região, ao contrário do que acontece nos complexos regionais.

Tendo como objectivo último a pacificação da Europa e a prossecução dos interesses nacionais, os líderes Europeus criaram acordos formais para a paz e a segurança que reflectiam uma visão e um entendimento comuns sobre os valores e as normas (Dunquerque 1947, Tratado de Bruxelas em 1948, NATO em 1949). Além disso, seguiram por um caminho paralelo e complementar caracterizado pela institucionalização, a barmonização, a integração e a normativização. A institucionalização é o processo através do qual um conjunto de mecanismos formais de tomada de decisão é estabelecido, de forma a iniciar, fomentar ou implementar políticas comuns. A harmonização diz respeito à crescente convergência das políticas nacionais em determinados assuntos. A integração é o processo através do qual os Estados Nação abdicam da sua soberania nacional em prol de uma instância supranacional. Por último, a normativização é definida como a prática que prevê a criação formal de princípios comuns ou até de uma ideologia comum. Estes quatro processos correlativos marcam um ponto de viragem na Europa, uma vez que simbolizam a nova Europa que inverteu um passado (complexo regional) onde os interesses nacionais eram alcançados através da concorrência, desconfiança e na forma de soma nula. 


\section{Europa: uma comunidade regional}

$\mathrm{Na}$ passagem de uma sociedade regional para uma comunidade regional, três grandes transformações ocorrem quanto aos instrumentos e agentes de paz. Primeiro, a institucionalização do processo de tomada de decisão, a harmonização das políticas nacionais e a transferência de soberania para os organismos da União tornam-se mais fortes e ganham contornos de supranacionalidade. Em segundo lugar, um sentimento transversal de comunidade ("we-ness") emerge (Deutsch et al., 1957). Como consequência da integração, harmonização, institucionalização e normativização europeias, os povos de uma região são envolvidos por princípios semelhantes de identificação e desenvolvem uma 'comunidade de segurança estreita" (Adler e Barnett, 1998). Em terceiro lugar, como consequência dos dois factores anteriores, a paz intra-regional e inter-estatal é dada como garantida.

Como consequência da contribuição dada por diversos actores (Estados, actores económicos privados, sociedade civil, UE) e dos diversos instrumentos de construção europeia, as guerras entre Estados, no contexto da União Europeia, são eliminadas. Numa comunidade regional, a paz negativa é assumida como natural e os actores regionais envolvem-se em actividades que podem gerar a paz positiva. As relações internacionais regionais podem, enfim, resultar de políticas externas dirigidas à promoção do bem-estar, definido em termos de rendimento per capita, emprego, educação, protecção de recursos naturais ou saúde. A partir daí, a articulação entre paz e regionalismo ultrapassa as fronteiras cognitivas e físicas da região. Enquanto "zona de paz" ou enquanto comunidade de segurança (Deutsch et al., 1957; Adler e Barnett, 1998; Wæver, 1998: 93), a União Europeia torna-se consciente da sua responsabilidade internacional, atinge o estatuto de actor internacional e comporta-se como tal na cena mundial.

Enquanto agente potencial de paz, a UE, está potencialmente comprometida com a promoção da paz e a gestão dos conflitos. São vários os instrumentos ao seu serviço, para este fim, seja enquanto potência militar, normativa (Rosencrance, 1998: 22; Manners, 2002; Petiteville, 2003) ou civil3 (Maull, 1990; Whitman, 2004; Nicolaidis e Howse, 2002).

Diplomacia directa. Após o Tratado de Amesterdão, a criação do Alto Representante para a PESC tem vindo a balizar (embora ainda de forma

\footnotetext{
${ }^{3}$ Hans W. Maull (1990) define uma potência civil como aquela que contém três características principais: a) a aceitação da necessidade de cooperação com os outros para a obtenção de objectivos internacionais; b) estar centrada em meios não militares, sobretudo económicos, para garantir os objectivos nacionais; c) disponibilidade para desenvolver estruturas supranacionais para tratar questões de gestão internacional.
} 
algo incipiente) a política externa dos membros da UE. De acordo com o Artigo J.13, o seu papel é "contribuir para a formulação, preparação e implementação de decisões sobre políticas".

Cooperação para o Desenvolvimento. Uma vez que a ajuda pode ter impactos directos ou indirectos nos conflitos violentos locais (Anderson 1999), o âmbito de acção dos aglomerados regionais nesta área deveria ser bivectorial. Por um lado, deveriam apoiar e supervisionar as ONG nacionais e internacionais que têm responsabilidades directas e indirectas no que diz respeito a iniciativas de paz de base ("bottom-up"). Por outro lado, é crucial o estabelecimento de uma política de desenvolvimento e prevenção de conflitos global coerente. No caso da UE, a Comissão tem que reforçar as disposições relativas à construção da paz e prevenção de conflitos (Artigo 11) consignadas no Acordo de Cotonou 4 .

Capacidades militares e civis. No seguimento da Política Europeia de Segurança e Defesa (PESD, fundada no Conselho Europeu de Colónia, Junho 1999) os Chefes de Estado e de Governo decidiram, primeiro, em Helsínquia (Dezembro de 1999) apoiar política, militar e financeiramente o estabelecimento de uma Força de Reacção Rápida, capaz de implementar todas as Missões de Petersberg. Foi também decidida, no Conselho Europeu da Feira (Junho de 2000), a criação de equipas civis internacionais de policiamento, administração civil e de implementação do Estado de direito e de protecção civil. Activa desde Janeiro de 2003, a Missão de Polícia da União Europeia na Bósnia (MPUE) representa a primeira operação civil de gestão de crises no contexto da PESD. Desde Dezembro de 2003, a UE leva ainda a cabo outras operações de polícia (EUPOL) na Ex-República Jugoslava da Macedónia (que foi precedida pela operação Concordia, a primeira missão militar da UE sob a égide da PESD) e lançou, em Julho de 2004, a Missão da União Europeia para o Estado de Direito na Geórgia no contexto da PESD. Outra operação militar foi ainda levada a cabo na República Democrática do Congo (Junho a Setembro de 2003), como preparação de uma operação reforçada das Nações Unidas (MONUC - Missão das Nações Unidas na República Democrática do Congo). Ainda com maior expressão, foi lançada uma operação militar na Bósnia, após a SFOR, no final de 2004.

\footnotetext{
${ }^{4}$ O Acordo de Cotonou foi estabelecido entre a União Europeia e os Países de África, Caraíbas e Pacífico (ACP) em Junho de 2000. Pretende promover e agilizar o desenvolvimento económico, social e cultural dos Estados ACP, contribuindo para a paz e segurança e promovendo um ambiente político estável e democrático (disponível on-line em http://www.acpsec.org/gb/cotonou/ accord1.htm; última visita em 10 de Setembro de 2003).
} 
Prevenção de Conflitos. A codificação de um interesse geral na prevenção de conflitos e nos processos de construção da paz surgiu com a "Comunicação sobre Prevenção de Conflitos” adoptada em Abril de 2001 pela Comissão, inspirada na iniciativa da Presidência Sueca de desenvolver um "Programa da União Europeia para a Prevenção de Conflitos Violentos"s. A lista de meios para a prevenção de conflitos à disposição da UE é longa: cooperação para o desenvolvimento e ajuda humanitária, instrumentos comerciais, políticas sociais e ambientais, acções diplomáticas e diálogo político, cooperação com os parceiros internacionais e as ONG, bem como os novos instrumentos no campo da gestão de crises (International Alert e SaferWorld 2003).

Cooperação Institucional. A prevenção de conflitos é uma tarefa demasiado complexa para uma só organização. Só uma coordenação efectiva entre parceiros internacionais pode ajudar a atingir este objectivo. Este facto foi reconhecido no Programa da União Europeia para a Prevenção de Conflitos Violentos, no qual pode ler-se que "[a] UE intensificará a troca de informação e a cooperação prática com o sistema das Nações Unidas, a OSCE, o Conselho da Europa, outras organizações regionais e sub-regionais e as instituições financeiras internacionais [...] no campo da prevenção de conflitos e gestão de crises".

Sanções. A União Europeia tem uma capacidade autónoma de aplicar sanções aos países não-membros, de modo a influenciar o rumo dos acontecimentos. As sanções podem ser de ordem política, cultural, financeira, económica, militar (embargo de armas) ou diplomática. A União Europeia tem como base legal para a activação destas medidas o Tratado que estabelece a Comunidade Europeia (TCE) ou o Tratado da União Europeia (Arts. 12 e 15 sobre "Posições comuns"). Actualmente, 21 países são objecto das sanções da União Europeia: Bielorússia, Bósnia-Herzegovina, Birmânia/ Miamar, China, República Democrática do Congo (Zaire), Costa do Marfim, Croácia, Haiti, Iraque, Libéria, Líbia, ex-República Jugoslava da Macedónia, República Federal da Jugoslávia, Moldávia, Sérvia e Montenegro, Serra Leoa, Somália, Sudão, Estados Unidos e Zimbabué.

Projecção de poder normativo. De modo a propagar os princípios normativos em que se baseia (liberdade, democracia, Estado de direito, direitos humanos, paz), a União Europeia recorre a uma série de estratégias: a) promoção de projectos regionais noutras partes do mundo e/ou envolvimento em relações inter-regionais; b) difusão de comunicações estra-

\footnotetext{
5 Disponível on-line em www.utrikes.regeringen.se/prefak/files/EUprogramme.pdf. Última visita em 10 de Setembro de 2003.
} 
tégicas ("policy papers”, declarações políticas); c) presença diplomática em países estrangeiros através de delegações, missões ou embaixadas; d) assistência financeira através, por exemplo, dos programas Phare e Tacis com o objectivo de promover a convergência com o acervo comunitário.

\section{Europa: entidade política regional institucionalizada}

No contexto da actual política global, este tipo de PRAS apresenta-se mais como uma hipótese teórica do que uma realidade empírica. Uma entidade política regional institucionalizada é um Estado federal cuja legitimidade provém da vontade comum de uma sociedade civil regional transnacional. A integração social antecede a partilha política. Provém da vontade de unificar as pessoas, as quais estão dispostas a maximizar as vantagens da sua integração e a criar mecanismos para gerir os conflitos que advêm da sua heterogeneidade.

Em termos institucionais, uma entidade política regional institucionalizada não deveria ter apenas como objectivo restrito transportar as autoridades nacionais do Estado para o nível macro-regional, deveria, sim, criar interacções políticas triangulares entre micro-regiões (ou comunidades, länder, estados, condados, províncias ou "nacionalidades" ${ }^{6}$ ), os antigos Estados nacionais e o governo central regional. De acordo com o princípio europeu da subsidiariedade, segundo o qual a tomada de decisão política deve ser praticada no nível mais próximo possível do cidadão, as micro-regiões poderiam desempenhar um papel vital no bom funcionamento da Europa.

Tal como demonstrado, a transformação gradual da Europa numa entidade política institucionalizada é certamente previsível partindo do pressuposto de que a violência nunca mais será usada para resolver conflitos entre Estados. Este sucesso notável na UE desvia frequentemente a atenção da incapacidade da mesma para lidar com conflitos dentro dos Estados. Nenhum dos instrumentos e actores regionais para a paz, dentro do espectro do complexo regional - comunidade regional, teve sucesso na abordagem de conflitos intra-estatais (ou tentou sequer fazê-lo de forma deliberada). Enquanto se vangloria do seu passado na construção da paz inter-estatal, a União Europeia esquece que os conflitos internos ainda existem dentro da União. Vários grupos étnicos/nações ainda lutam, violenta ou pacificamente, por uma melhor distribuição do poder ou pela independência política na Europa: Corsos e Bretões em França; Bascos, Galegos e Catalães em

\footnotetext{
${ }^{6}$ É assim que a Constituição espanhola forja, de forma ambígua, o carácter político e étnico distinto das suas regiões (Forsyth, 1989: 30-31).
} 
Espanha; Católicos na Irlanda do Norte; Flamengos e Valões na Bélgica; Sardenhos e Tiroleses do Sul; habitantes da Cornualha e Escoceses no Reino Unido; ou os Saamis na Noruega, Suécia e Finlândia. Este artigo defende que uma entidade política regional institucionalizada constitui uma forma viável de gerir estas exigências. Isto por uma razão fundamental: o governo e a governação regionais não partem de uma abordagem estatal. Tal como demonstrei, são compostos por uma série de actores que incluem comunidades locais e regiões nacionais, combinadas com redes, grupos de pressão, organizações da sociedade civil e formas mais abrangentes de organização política. Tal como Marks et al. assinalaram, "o Estado já não monopoliza as tomadas de decisão políticas de âmbito europeu nem a exacerbação dos interesses nacionais" $(1996,346)$. A crescente integração da Europa leva a fronteiras mais porosas e a novas configurações de poder que, consequentemente, conduzem a uma limitação da ortodoxia intergovernamental (Loughlin, 1993: 15). Neste quadro, as comunidades locais, em vez de entrarem em confronto com os interesses estatais, passam a ter acesso a instituições de "policy-making" (Bullman, 1997; Keating, 1998; Marks e Hooghe, 1996).

\section{Conclusão}

Uma das dificuldades de abordar de forma coerente a estrutura de uma paz europeia provém do facto de os pilares dessa paz e a área em que estão fundados não coincidirem necessariamente em termos geográficos e de orientação orgânica. O quadro de análise aqui apresentado foi aplicado à Europa construída pela UE da perspectiva da integração regional. No entanto, existem mais Europas dentro da Europa e mais pilares de segurança do que aqueles centrados na União Europeia. O mais completo de todos, geográfica e funcionalmente, é a Organização para a Segurança e Cooperação na Europa (OSCE). Esta é a única organização regional na Europa que se considera, ela própria, um acordo regional sob a égide do Capítulo VIII da Carta das Nações Unidas e que é orientada para o alerta precoce, a prevenção de conflitos, a observação de eleições, a democratização e a gestão de conflitos. Compreende 55 membros, cobrindo uma área geográfica que vai desde os Estados Unidos e o Canadá até à Rússia e Ásia Central. Para além da UE e da OSCE, o terceiro pilar da segurança europeia situa-se na "nova NATO/OTAN". O mais recente conceito estratégico da NATO, adoptado em 1999, retirou a Aliança do papel restrito de defesa em conjugação com a Europa Ocidental/União Europeia. Desde 1999, a NATO pode levar a cabo "operações de resposta a crises", tal como fez nos Balcãs e recentemente no Afeganistão. A forma como estes pilares são incor- 
porados neste quadro depende do modo de conceptualizar esta região. Se o vasto espaço político composto por todos os países que constituem a mais abrangente organização de segurança quanto ao número de membros, a OSCE, é suposto ser constituído, não por um PRAS, mas por vários (América do Norte, União Europeia, Cáucaso e Ásia Central), então, este quadro de análise deve ser aplicado individualmente a cada PRAS. Foi isso que fiz partindo do caso da União Europeia. Se, por outro lado, os vastos espaços que vão de Vancouver ao Leste da Europa (no caso da NATO) ou de Vancouver ao Quirguistão (no caso da OSCE) forem considerados PRAS, com um "certo grau de singularidade", então a NATO e a OSCE deverão ser consideradas enquanto instrumentos institucionais formais para a paz numa dada sociedade regional.

\section{Referências Bibliográficas}

Adler Emanuel; Barnett, Michael (1998), Security Communities. Cambridge / New York: Cambridge UP.

Bullman, U. (1997), "The Politics of the Third Level", Regional and Federal Studies, 6(2).

Buzan, Barry et al. (1990), The European Security Order Recast: Scenarios for the Post-Cold War Era. London / New York: Pinter Publishers.

Deutsch, Karl et al. (1957), Political Community and the North Atlantic Area. Princeton: Princeton UP.

Evera, Stephen van (1990/91), 'Primed for Peace: Europe after the Cold War' in International Security 15(3), 7-57.

Final Act of The Conference on Security and Cooperation in Europe (1975), Helsinki (http://www.osce.org/docs/english/1990-1999/summits/helfa75e.htm\#Anchor29952; último acesso em 28/11/03).

Forsyth, Murray (org.) (1989), Federalism and Nationalism. Leicester / London: Leicester UP.

Gaddis, J.L. (1987), The Long Peace: Inquiries into the History of the Cold War. New York: Oxford UP.

Gleditsch, N.P. (1995), "Democracy and the Future European Peace”, European Journal of International Relations, 1(4).

Hettne, Björn (org.) (1988), Europe: Dimensions of Peace. London / New Jersey: The United Nation University.

Holsti, Kalevi J. (1991), Peace and War: Armed Conflicts and International Order 1648-1989. Cambridge: Cambridge UP.

Kacowicz, Arie M. (1998), Zones of Peace in the Third World: South America and West Africa in Comparative Perspective. New York: State University of New York Press. 
Keating, M. (1998), The New Regionalism in Western Europe: Territorial Restructuring and Political Change. Cheltenham: Edward Elgar.

Lake, Davis; Patrick Morgan (1997), Regional Orders: Building Security in a New World. University Park, PA: Pennsylvania State UP.

Loughlin, J. (1993), "Federalism, Regionalism and European Union”, Politics, 13(1).

Manners, Ian (2002), “Normative Power Europe: A Contradiction in Terms?”, Journal of Common Market Studies, 40(2).

Maoz, Z.; Russett, Bruce (1992), “A 'New World Order': From Balancing to Hegemony, Concert or Collective Security”, International Interactions, 18.

Marks, G.; Hooghe, L. (1996), "Europe with the Regions: Channels of Regional Representation in the European Union”, Publius - The Journal of Federalism, 26(1).

Marks, G.; Hooghe, L.; Blank, K. (1996), "European Integration from the 1980s: State-Centric vs. Multi-Level Governance”, Journal of Common Market Studies, 34(3).

Maull, H. (1990), "Germany and Japan: The New Civilian Powers", Foreign Affairs, 69(5).

Mearsheimer, J. J. (1990), "Back to the Future: Instability in Europe after the Cold War”, International Security, 15(1).

Mouritzen, Hans (1995), A Fallacy of IR Theory: Reflections on a Collective Repression. Copenhagen: Center for Peace and Conflict Research (ms.).

Nicolaidis Kalypso; Robert Howse (2002), "This is my EUtopia...: Narrative as Power", Journal of Common Market Studies, 40(4).

Petiteville, Franck (2003), “'Exporting 'Values'? EU External Co-operation as a 'Soft Diplomacy”, in Michele Knodt; Sebastiaan Princen (orgs.), Understanding European Union's External Relations, London/New York: Routledge.

Rosencrance, R. (1998), “The European Union: A New Type of International Actor”, in Jan Zielonka (org.), Paradoxes of European Foreign Policy. Hague: Kluwer Law International.

Singer, Max; Aaron Wildavsky (1993), The Real World Order: Zones of Peace, Zones of Turmoil. New Jersey: Chantam House Publishers.

Wæver, Ole (1998), "Insecurity, Security, and Asecurity in the West European Non-war Community", in Emmanuel Adler; Michael Barnett (orgs.), Security Communities. Cambridge / New York: Cambridge UP.

Waltz, Kenneth (1993), “The Emerging Structure of International Politics” International Security, 18(2), 44-79.

Whitman, Richard (2002), "The Fall and Rise of Civilian Power Europe” (http:// fesportal.fes.de/pls/portal30/docs/folder/politikanalyse/paxamericana/whitman.pdf; consultado em 23/8/04). 